\title{
Challenges, Coping Strategies, and Needs of Mothers with Children with Attention Deficit Hyperactivity Disorder: Implications for Intervention
}

\author{
Maribi Maria Benita Balagan', Maria Caridad Tarroja ${ }^{2}$ \\ ${ }^{1}$ Cagayan State University, Tuguegarao City, Philippines \\ ${ }^{2}$ De La Salle University, Manila, Philippines \\ Email:mariabenitabalagan@csu.edu.ph,mariacaridadtarroja@dlsu.edu.ph
}

How to cite this paper: Balagan, M. M. B., \& Tarroja, M. C. (2020). Challenges, Coping Strategies, and Needs of Mothers with Children with Attention Deficit Hyperactivity Disorder: Implications for Intervention. Open Journal of Social Sciences, 8, 24-35.

https://doi.org/10.4236/jss.2020.812003

Received: July 8, 2020

Accepted: December 6, 2020

Published: December 9, 2020

Copyright $\odot 2020$ by author(s) and Scientific Research Publishing Inc. This work is licensed under the Creative Commons Attribution International License (CC BY 4.0).

http://creativecommons.org/licenses/by/4.0/

(c) (i) Open Access

\begin{abstract}
Attention deficit hyperactivity disorder (ADHD) is a lifelong disorder; hence, poor management may lead to adverse functional outcomes that may persist into adulthood. Pediatric ADHD is a major stressor for parents and may result in a problematic parent-child interaction. Therefore, the aim of this study, which employed the consensual qualitative research method, was to explore the challenges, coping strategies, and needs of mothers with children diagnosed with ADHD. The participants were 10 mothers with children with ADHD aged 6 - 11 years, selected through purposive sampling. Data from in-depth interviews were analyzed and the domains and categories were identified. The results indicated that major challenges for mothers included the child's academic problems, physical aggressiveness, stubbornness, as well as the family's financial difficulties. Participants used both adaptive and maladaptive strategies to cope with their hampered physical, emotional, and social well-being. Based on the findings, mothers' most pressing needs are education related to ADHD and improving their parenting skills; hence, a psychoeducational program on parenting, awareness about ADHD, and self-management is proposed.
\end{abstract}

\section{Keywords}

Attention Deficit Hyperactivity Disorder, Caregiver Challenges, Caregiver Coping Strategies, Caregiver Needs, Interventions for Caregivers

\section{Introduction}

Attention Deficit Hyperactivity Disorder, or ADHD, is a neurodevelopmental 
disability that affects both children and adults. It is characterized by a persistent pattern of inattention and/or hyperactivity-impulsivity that is more frequently manifested and more severe than is typically observed in individuals of a comparable level of development (DSM-5, 2013). The Diagnostic Statistical Manual (DSM-5, American Psychiatric Association, 2013) classifies ADHD into the following subtypes: the combined type, which is characterized by inattentiveness and hyperactivity-impulsivity; the predominantly inattentive type; and the predominantly hyperactive-impulsive type. It is a life-long disorder; hence, poor management may lead to adverse functional outcomes, as the child moves towards adolescence and adulthood. Its treatment and management are likewise crucial as the disorder often exists with co-morbid conditions, the most prevalent being the oppositional defiant disorder, conduct disorder, and anxiety disorders (Wells et al., 2006).

One of the most severe consequences of pediatric ADHD is parental stress, which leads to a problematic parent-child interaction (Barkley, 2006; Wells, 2005). Compared to their typically developing peers, children with ADHD are less compliant, or sustain their compliance only for short periods; they are less likely to remain on task and display more negative behaviors. Given these behavioral issues, parental distress and interactional conflict are relatively common in families with children with ADHD. Parental distress, resulting from a lack of emotional preparation and inadequate knowledge and skills concerning caring for the child with ADHD, can be particularly detrimental to family relations. In Wymbs et al.'s (2008) study, parents who had a child with ADHD were not only more likely to divorce, but also had a shorter latency to divorce than parents of children without ADHD.

Furthermore, the risk of the child with ADHD engaging in dysfunctional behavior may be a source of worry for parents. In this context, it can be assumed that both parental psychological health and parenting behaviors are an environmental risk or protective factors on the developmental outcomes of ADHD, particularly with regard to the emergence and the course of conduct problems (Johnson \& Mash, 2001).

Generally, the mother assumes the greater share in the caregiving responsibility. Hence, being the primary caregiver, she is the one most affected by the child's condition. As pointed out by Gerald Patterson (1982) in his theory of coercive family process, mothers following repeated unsuccessful interactions with their difficult children either withdraw, or respond with hostility, causing the child's behavior to escalate. Over time, the maladaptive behavior of both the child and the mother are reinforced, which strengthens and escalates the coercive cycle. Chronis et al. (2007) also showed that maternal depression is a risk factor, whereas early positive parenting is a protective factor for the developmental course of conduct problems among children with ADHD. Therefore, the dysfunctional parenting behavior and problematic parent-child interaction may result in coercive interaction; hence, may worsen the maladaptive behaviors of children with ADHD. 
Behavioral management training has been shown to be effective in the context of families with ADHD. A study based on Behavioral Management Flow Chart Model, which incorporated requests, praise or warning, and time-out procedures reported reduction in disruptive behavior of the ADHD child. Likewise, parenting behavior improved and parenting stress decreased. In Stattin et al.'s (2015) study, parents who received behavioral management intervention showed considerably fewer negative behaviors toward their children at posttest compared with pretest; further, conduct problems in the child with ADHD were strongly reduced. The participants in the study showed increased parental competence and decreased stress and depressive symptoms.

\section{Problem Statement}

In this study, we explored the experience of mothers who have a child with ADHD.

Specifically, the study sought to answer the following questions:

1) What are the challenges encountered by mothers with a child diagnosed with ADHD?

2) How are the mothers affected physically, emotionally, and socially?

3) How do the respondents cope with the challenges of having a child with ADHD?

4) What are the needs of mothers with a child with ADHD?

5) What psycho-educational intervention can be developed based on the respondents' needs?

\section{Methods}

\subsection{Sample}

Purposive, non-probability sampling was used to identify 10 mothers of children diagnosed with ADHD. Mothers whose children were enrolled in five schools covered by the study were identified by their special education teachers. The inclusion criterion was a diagnosis of ADHD, either by a developmental pediatrician or a child psychologist, for at least one year. Mothers were excluded from the study if their child had 1) a known comorbid diagnosis of neurological, serious medical, or psychiatric disorders, or 2) physical disease or illnesses that required medical or parental intervention.

The participants' age range was 33 to 37 , with a mean of 33.5 years. Their children were aged 6 to 11 years with a mean of approximately seven. Of the 10 children, eight were male and two were female. Most children were diagnosed with combined ADHD; three were inattentive, and two hyperactive.

\subsection{Procedure}

The mothers were selected and contacted through the teachers of special education classes in private and public elementary schools. The interview guide incorporated both English and Filipino. To ensure the trustworthiness of the ga- 
thered data, the interview guide was pilot-tested and evaluated by an external auditor. After obtaining the recommendations of the external auditor, the researchers visited the participants and showed them the preliminary analyses.

\subsection{Data Analysis}

The consensual qualitative research approach proposed by Hill et al. (2005) was employed. The steps involved were: 1) identifying domains and themes to cluster data, 2) developing the core ideas that would capture the essence of the participant's voices, and 3) cross-analysis that involves constructing categories that describe common themes across the sample (Ponterotto, 2010). The data was classified as "general" (8 - 10 responses); "typical" (5 - 7 responses); and "variant" (1 - 4 responses).

\subsection{Ethical Considerations}

The identified mothers were informed of the nature and objectives of the study, and were given a letter outlining their role and potential contribution to the ADHD community. They were assured of the confidentiality of their data, and permission to record the interview was sought. All participants provided written informed consent. The study was presented and approved by the Institutional Review Committee (five members).

\section{Result}

\subsection{Challenges of Mothers with Children Diagnosed with ADHD}

Two major categories pertaining to the challenges mothers faced in parenting their child with ADHD were identified. The first concerned the child's characteristics, including behavioral and school-related problems, and the second was related to life circumstances, such as financial difficulties and family relationships.

\subsubsection{Characteristics of the Child}

The poor academic performance of children with ADHD, resulting from learning problems, was a commonly reported source of stress. Altogether, mothers attributed their children's poor academic performance to distractibility, hyperactivity, stubbornness, and physical aggression (Table 1).

"Mababa ang grades niya..napansin ko na noong nag aral siya..lagi akong sinasabihan ng teacher niya na ipa assess ko daw... parang di daw kasi siya maka focus... di nagsusulat at mababa grade niya sa Math" (He has poor grades... he does not take notes or copy from the board... he is bad in Math.).

\subsubsection{External Circumstances}

In this category, financial constraints were a major source of stress. Ensuring adequate care for the child, which involved seeking professional help, medication, and treatment was mother's primary concern. However, support from their immediate kin helped them meet their basic needs. 
Table 1. Domains and categories on the challenges encountered by the respondents.

\begin{tabular}{|c|c|c|c|}
\hline Challenges & Categories & Frequency & Descriptors \\
\hline \multirow[t]{11}{*}{ Child's Characteristics } & Hyperactivity & 7 & Typical \\
\hline & Stubbornness & 6 & Typical \\
\hline & Poor School Performance & 9 & General \\
\hline & Delayed Speech Development & 3 & Variant \\
\hline & Delayed Motor Development & 1 & Variant \\
\hline & Physical Aggression & 7 & Typical \\
\hline & Short Attention Span & 6 & Typical \\
\hline & Self-harm & 1 & Variant \\
\hline & Forgetfulness & 4 & Variant \\
\hline & Distracted by Technology & 2 & Variant \\
\hline & Sleep Problems & 1 & Variant \\
\hline \multirow[t]{5}{*}{ External Circumstance } & Financial Condition & 7 & General \\
\hline & Marital Problems & 3 & Variant \\
\hline & Problems with Family and Relatives & 4 & Variant \\
\hline & Bullying & 2 & Variant \\
\hline & Social Stigma & 3 & Variant \\
\hline
\end{tabular}

Note: $\mathrm{N}=10$; A category is identified as "general" if it applied to 8-10 cases, "typical" if it applied to 5-7 cases, and "variant" if it applied to 4 or less cases.

\subsection{Impact on Well-Being}

To gain a comprehensive understanding of the mothers' coping strategies, the impact of having a child with ADHD on physical, emotional, and social well-being was investigated. Mothers' physical well-being was generally affected as they experienced fatigue in caring and parenting their child. Likewise, they felt frustrated, worried and uncertain of their child's future. Moreover, they tended to limit their social activities to give more time to their child. However, the impact of having an ADHD child in the family varied across the respondents; most mothers indicated that having a child with ADHD had positive consequences with regard to family cohesion and coordination (Table 2).

"Di ko alam...madalas sumasakit likod ko...sabi nila dahil sa stress ito...di ko masyadong naramdaman ito noon.pero madalas nanakit ngayon." (I don't know...but I often have this pain on my lower back...they say it is due to stress... I did not have this before... recently, the pain has become recurrent.)

"Kung minsan nawawalan ako ng gana... minsan nanaginip ako... umiiyak dahil sa kundisyon ng anak ko... kung minsan ayaw kong magtrabaho... nasa kuwarto lang ako..natutulog." (At times, I feel no zest at all... on one occasion, I saw myself crying in my dreams over my daughter's condition... sometimes I would not want to work, but spend the day in my room and sleep.) 
Table 2. Domains and categories of the impact of having an adhd child on the mother's well-being.

\begin{tabular}{cccc}
\hline Impact & Categories & Frequency & Descriptor \\
\hline Physical & Fatigue & 10 & General \\
Emotional & Somatic Pain & 4 & Variant \\
& Frustration & 8 & General \\
& Uncertainty about the child's future & 7 & Typical \\
& Worry & 5 & Typical \\
Sadness & Self-blame & 2 & Variant \\
& Guilt & 1 & Variant \\
& Difficulty in managing anger in giving discipline & 1 & Variant \\
& Learning to manage emotions & 3 & Variant \\
& Developed patience and understanding & 3 & Variant \\
Locial & Less social Activities & 10 & Variant \\
& Social Avoidance & 1 & General \\
& Facing Social Stigma & 2 & Variant \\
& Dariant \\
\hline
\end{tabular}

Note: $\mathrm{N}=10$; A category is identified as "general" if it applied to 8 - 10 cases, "typical" if it applied to 5 - 7 cases, and "variant" if it applied to 4 and less cases.

"Ok lang family ko...yung parents ko... si tatay siya yung nagdidisiplina kung minsan... sa brother ko siya close... accept na naman nila kalagayan ni Adrianne." (My family helps me in taking care of my child... my father disciplines him at times... he is close to my brother...they have learned to accept Adrianne's condition.)

\subsection{Coping Strategies}

Coping strategies refer to how mothers meet the challenges that could impact their well-being. These may be classified as adaptive and maladaptive. Adaptive coping strategies involved efforts to meet problems squarely by resorting to mechanisms to alleviate the effects of the problem and to avoid occurrence of more serious problems. Maladaptive strategies are efforts of temporarily addressing the problem through ineffective means (Table 3).

Adaptive strategies involved seeking information from professionals, trying to be optimistic, family coordination, religiosity, and self-care. The mothers generally reported information seeking and availing professional services as their coping strategies. The results further highlighted the fact that family coordination lightens the burden of parenting a child with ADHD.

"Nagtanong-tanong ako sa mga guro ng anak ko kung paano ako makakuha ng discounted consultation fees...ni-refer nila ako sa STAC..nakakuha ako ng libreng services ng occupational therapist." (I tried to inquire from other parents and from his teachers about whom to approach for help. His teacher advised me to bring him to STAC. I was able to get free services from their occupational therapist.) 
Table 3. Domains and categories of the respondents' coping strategies.

\begin{tabular}{cccc}
\hline Coping Strategies & Categories & Frequency & Descriptor \\
\hline Adaptive & Early Acceptance & 3 & Variant \\
Gradual Acceptance & 2 & Variant \\
Optimism & 7 & Typical \\
Family Coordination & 5 & Typical \\
Religiosity & 4 & Variant \\
Self-Care & 4 & Variant \\
Information-Seeking & 8 & General \\
Availing Professional Services & 7 & Typical \\
Denial & 8 & General \\
Maladaptive & Rationalization & 4 & Variant \\
Social Avoidance & 1 & Variant \\
\hline
\end{tabular}

Note: $\mathrm{N}=10$; A category is identified as "general" if it applied to $8-10$ cases, "typical" if it applied to 5 - 7 cases, and "variant" if it applied to 4 and less cases.

Maladaptive coping strategies may be in the form of denial, rationalization, and social avoidance. Initially, mothers coped by believing that their child's condition was not serious and that their child only manifests behaviors that were not observed in others. As mentioned by one participant,

"Nung nalaman ko sa duktor... nag-alala ako... pero ang alam ko di naman talaga malalala...hindi naman abnormal anak ko." (When I learned about my daughter's condition from the doctor, I was worried, but I thought, "her condition is not really serious unlike other disorders... my daughter is not abnormal.")

\subsection{Needs of the Mothers}

The mothers were concerned about how they could learn skills required to parent their child with ADHD, such as managing behaviors and determining strategies to support their child in school. Additionally, they wanted to improve their knowledge about the nature and cause of ADHD (Table 4). Although they sought professional information and help, they wished to develop effective parenting strategies to address problems relating to parent-child interaction.

"Pano kaya maging mabuting magulang sa mga katulad ng anak ko... gusto

ko din matuto paano siya i-handle." (How can one be a good parent to kids like him? I want to learn.)

As mothers were still confused about the nature of their child's condition, they believed that being more informed would help them in carrying their parenting duties. As pointed out by one of them, "I told myself... maybe ADHD... lack of attention... that is probably why he is behaving that way... he seeks attention from the teacher." 
Table 4. Domains and categories of the respondents' parenting needs.

\begin{tabular}{cccc}
\hline Needs & Categories & Frequency & Descriptor \\
\hline Informed Parenting Skills & Managing child's difficult behavior & 9 & General \\
& Strategies to support child in school & 9 & General \\
$\begin{array}{c}\text { Improved Knowledge } \\
\text { of the Child's Condition }\end{array}$ & $\begin{array}{c}\text { Understanding the nature } \\
\text { and cause of ADHD }\end{array}$ & 8 & General \\
& Understanding its treatment and cure & 8 & General \\
Self-Improvement & Becoming a better parent & 1 & Variant \\
\hline
\end{tabular}

Note: $\mathrm{N}=10$; A category is identified as "general" if it applied to 8-10 cases, "typical" if it applied to 5 - 7 cases, and "variant" if it applied to 4 cases or less.

\section{Discussion}

\subsection{Mothers' Challenges}

According to the literature on raising a child with ADHD, these mothers experience more stress than those of typically developing children. For instance, Whalen et al. (2006) reported elevated symptomatic behaviors, such as hyperactivity, inattentiveness, lack of concentration, aggressiveness, and negative moods, combined with lower parenting effectiveness and quality of life among parents of children with ADHD. In the present study, the two domains that constituted the challenges and sources of stress were the child's characteristics and external circumstances. Poor school performance, stubbornness, and physical aggressiveness are the child-related characteristics that usually cause stress among the mothers. As pointed out by Silver (2004), children with ADHD may experience learning disabilities and other psychiatric symptoms, such as anxiety and depression.

In general, parents' expectations of their school-aged children are centered on academic performance. In this study, as the children were school-aged, guiding them in the performance of school tasks was exhausting for mothers. The children's stubbornness increased mothers' daily stress. Getting the child ready for school on a daily basis was difficult for mothers. This finding is in line with Barkley's (2006) observation that children with ADHD usually display defiance and impulsivity. These features of ADHD are the main cause of concern for parents and teachers (Barkley, 2006). Furthermore, the child's stubbornness and externalizing behaviors often lead to a coercive parent-child interaction, increasing parenting stress (Barkley, 2000). Although the overall themes regarding the challenges and stressors of mothers appear similar to previous studies, individual situations may differ.

Life situations, such as those relating to finances, were a typical category contributing to participants' stress. This finding runs parallel with the study conducted by Smith et al. (2001), wherein factors such as income, time available for interactions with the child, and social support, predicted parenting stress. In addition, according to another study, mothers with lower educational levels reported more stress (Phetrasuwan \& Mies, 2009). Although a link between in- 
come and parenting stress was not established in the present study, participants generally reported that financial condition is a barrier to seeking professional help.

\subsection{Impact on Well-Being}

The impact of having a child with ADHD on mothers' physical well-being manifested in various ways, such as through fatigue and somatic symptoms, like in body pains, headaches, and back pains. It was evident that the mothers in this study generally experienced fatigue. They considered their role in caring for their child, assisting them in their studies, guiding them, and responding to their demands physically draining. Additionally, their emotional well-being was affected. Participants were likely to experience frustration and a sense of uncertainty about their child's future. This psychological impact was characterized by a fear of losing control over their child, feeling inadequate as a parent, and finding it difficult to manage their child's learning problems. The participants' inability to control their child's behavior resulted in feeling of helplessness and inadequacy. As postulated by Barkley (2000), parents of children with ADHD view themselves as less skilled and knowledgeable and derive less value and comfort in their parenting efforts, compared to parents with normal children. The impact on mothers' social well-being was evident in how they limited their social activities to devote more time with their child and family. They reduced engagement in activities with friends, became selective about social gatherings to attend, and set a limit on the time allotted for social activities. Medina (2001) postulated that childcare, in general, limits the time parents have for productive work or leisure activities. In the context of a child with ADHD, the consequence for the family may be positive or negative. In this study, though mothers did experience resentment and animosity, family cohesion was a positive implication. The child's behavioral problem may lead to family conflicts; however, conflict resolution may be a positive experience. Therefore, difficulties and struggles in families with children with ADHD are made lighter through family support and cohesion.

\subsection{Coping Strategies}

To cope with the burden of childcare, the participants resorted to adaptive mechanisms, such as being optimistic and hopeful that their child will outgrow and overcome the disability. Upon learning that their child has ADHD, the mothers initially tried to be optimistic despite their confusion about the nature of their child's condition. They consequently sought help from professionals, such as teachers, doctors, and psychologists.

Maladaptive coping may result in negative beliefs about ADHD. These maladaptive coping strategies include denial, rationalization, and social avoidance. This confirms Mychailyszyn et al.'s (2008) finding that though some parents were more intuitive in sensing that something was wrong, others maintained 
that there was nothing wrong with their child, even when they know what it was.

\subsection{Parenting Needs}

Mothers with children with ADHD primarily need to develop effective strategies for the management of behaviors such as the child's physical aggressiveness, hyperactivity, sleep disturbance, distractibility, developmental delay, impulsivity, self-harm, and hostility. As these behaviors are difficult to handle, they affect the mother's well-being. Hence, the participants in this study wished to join parenting programs that could help them become more effective and nurturing parents. They likewise expressed the need to develop new strategies to support their child in school. This is probably owing to the fact that one of the major concerns of mothers is centered on their child's academic difficulties. In line with this, Kattathara (2008) pointed out that ADHD symptoms create patterns of low self-esteem and poor social and academic skills, which may evoke frustration in parents; hence, they believe that support groups are the best option.

\subsection{Implications for Intervention}

Based on the needs of mothers with a child with ADHD identified in this study, interventions to assist them can be conceptualized. Among the participants in this study, needs were associated with their challenges, daily stress, and parenting skills. Thus, intervention must cover four major areas: 1) understanding the nature of $\mathrm{ADHD}, 2$ ) parenting techniques, 3) self-care and management, and 4) building a parent support group.

The participants did not have a clear understanding of their child's condition. Hence, the provision of adequate information on the nature of ADHD is necessary. It was apparent from their responses that they considered ADHD an abnormality-some form of mental retardation. Nonetheless, they consider it a less serious condition than autism. Moreover, the mothers expressed their desire to learn more effective parenting techniques, as they felt they were unable to manage their child with ADHD. In addition, practicing stress management and self-care were among the major concerns. Finally, because they had learned to limit their social activities, the mothers felt the need to join parent support groups, which would give them the opportunity to learn from other parents of children with ADHD.

\section{Conclusion}

Given the existing literature on the topic, this study makes a contribution through a description of the challenges, coping strategies, and needs of mothers with a child diagnosed with ADHD. Awareness of these aspects will help policy makers provide appropriate support and develop programs that may promote the welfare of mothers in difficult situations. The findings may increase family members' understanding and acceptance of the disorder, as well as enhance their ability to cope with the daily struggles of parenting a child with ADHD. More 
importantly, this study can encourage a collaborative relationship between counseling psychologists, mental health professionals, and mothers.

\section{Conflicts of Interest}

The authors declare no conflicts of interest regarding the publication of this paper.

\section{References}

American Psychiatric Association (2013). Diagnostic and Statistical Manual of Mental Disorders (5th ed.). Arlington, TX: American Psychiatric Publishing. https://doi.org/10.1176/appi.books.9780890425596

Barkley, R. A. (2000). A Guiding Philosophy of Parents of Children with ADHD. Taking Charge of ADHD, Revised Edition. The Complete Authoritative Guide for Parents. New York: Guilford Publications.

Barkley, R. A. (2006). Attention-Deficit Hyperactivity Disorder: A Handbook for Diagnosis and Treatment (3rd ed.). New York: Guilford Press.

Chronis, A., Pelham, W. E. Jr., Baumann, B. L., Kipp, H., Lahey, B. B., Williams, S. H., Jones, H., \& Rathouz, P. (2007). Maternal Depression and Early Positive Parenting Predict Future Conduct Problems in Young Children with Attention Deficit/Hyperactivity Disorder. Developmental Psychology, 23, 70-82. https://doi.org/10.1037/0012-1649.43.1.70

Hill, C. E., Thompson, B. J., Hess, S. A., Knox, S., Williams, E. N., \& Ladany, N. (2005). Consensual Qualitative Research: An Update. Journal of Counseling Psychology, 52, 196-205. https://doi.org/10.1037/0022-0167.52.2.196

Johnson, C., \& Mash, E. J. (2001). Families of Children with Attention Deficit/Hyperactivity Disorder: Review and Recommendations for Future Research. Clinical Child and Family Psychology, 4, 183-207. https://doi.org/10.1023/A:1017592030434

Kattathara, J. J. (2008). Experience of Indian Families with a Child Diagnosed with $A D H D$. Unpublished Doctoral Dissertation, Taft: De La Salle University.

Medina, B. (2001). The Filipino Family (2nd ed.). Quezon City: University of the Philippines Press.

Mychailyszyn, M. P., dosReis, S., \& Myers, M. (2008). African American Caretakers' Views of ADHD and Use of Outpatient Mental Health Care Services for Children. Family Systems \& Health, 4, 447-459. https://doi.org/10.1037/1091-7527.26.4.447

Patterson, G. R. (1982). Coercive Family Process. Eugene, OR: Castalia.

Phetrasuwan, S., \& Miles, M. S. (2009). Parenting Stress in Mothers of Children with Autism Spectrum Disorders. Journal for Specialist in Pediatric Nursing, 14, 157. https://doi.org/10.1111/j.1744-6155.2009.00188.x

Ponterotto, J. G. (2010). Qualitative Research in Multicultural Psychology: Philosophical Underpinnings, Popular Approaches and Ethical Considerations. Cultural Diversity and Ethnic Minority Psychology, 16, 581-589. https://doi.org/10.1037/a0012051

Silver, L. B. (2004). Attention Deficit Hyperactivity Disorder: A Clinical Guide to Diagnosis and Treatment for Health and Mental Health Professionals (3rd ed.). London: American Psychiatric Publishing Inc.

Smith, T. B., Oliver, M. N., \& Innocenti, M. S. (2001). Parenting Stress in Families of Children with Disabilities. American Journal of Orthopsychiatry, 71, 257-261.

https://doi.org/10.1037/0002-9432.71.2.257 
Stattin, H., Ozdamir, M., Enebrith, P., \& Gianotta, F. (2015). A National Evaluation of Parenting Program in Sweden: The Short-Term Effects Using an RCT Effectiveness Design. Journal of Consulting and Clinical Psychology, 83, 1069-1084. https://doi.org/10.1037/a0039328

Wells, K. C. (2005). Family Therapy for Attention Deficit/Hyperactivity Disorder (ADHD). In J. Lebow (Ed.), Handbook of Clinical Family Therapy. Englewood, NJ: Wiley.

Wells, K. C., Chi, T. C., Hinshaw, S. P., Epstein, J. N., Pfiffer, L., Schwalm, N. M., Owens, E. B., Eugene, L. A., Abikof, H. B., Conner, C. K., Elliot, G. R., Greenhill, L. L., Hechtman, L., Hoza, B., Jansen, P. S., March, J., Newcorn, J. H., Pelahm, P., Swere, J. B., Swanson, J., Vitiello, B., \& Wigam, T. (2006). Treatment Related Changes in Objectively Measured Parenting Behaviors in Multimodal Treatment Study of Children with Attention Deficit Hyperactivity Disorder. Journal of Consulting and Clinical Psychology, 74, 640-857. https://doi.org/10.1037/0022-006X.74.4.649

Whalen, C. K., Henker, B., Jhamner, L. D., Ishikawa, S. S., Floro, J. N., Swindle, R., Perwien, A. R., \& Johnson, J. A. (2006). Toward Mapping Daily Challenges of Living with ADHD: Maternal and Child Perspectives Using Electronic Diaries. Journal of Abnormal Child Psychology, 34, 115-130. https://doi.org/10.1007/s10802-005-9008-5

Wymbs, B. T., Pelham Jr., W. E., Molina, B. S., Gnagy, E. M., Wilson, T. K., \& Greenhouse, J. B. (2008). Rate and Predictors of Divorce among Parents of Youth with ADHD. Journal of Consulting and Clinical Psychology, 76, 735-744.

https://doi.org/10.1037/a0012719 